Long days produced vary short heads. In the winter wheat used, long days and the higher temperature often led to a failure to produce heads at all but resulted in the development of an elongated shoot with multiple vegetative branching at the nodes-a state similar to that commonly found in England in Agrostis, Festuca and Holcus during the autumn and called by Arber" the "pompon or mop habit".

\begin{tabular}{|c|c|c|}
\hline High & Long heads & $\begin{array}{c}\text { No heads + pompon } \\
\text { habit or } \\
\text { Short heads }\end{array}$ \\
\hline Low & $\begin{array}{l}\text { Long heads } 1 \\
\text { or } \\
\text { Branched heads }\end{array}$ & Short heads \\
\hline
\end{tabular}

If the above table represents the general interactions of day-length and temperature on wheat, then in homozygous branched-headed $T$. turgidum $(b h b h)$ the area of the rectangle 1 is comparatively large so that normal sowing will fall within these limits and miracle heads be produced. In the heterozygotes, $B h b h$, resulting from the cross normal $T$. vulgare $(B h B h) \times$ branched-headed $T$. turgidum $(b h b h)$ the rectangle is smaller, so that in the greenhouse, at any rate, only early sowing will give miracle heads; tiller heads from early-sown plants and main and tiller heads of late-sown plants will be developing under conditions outside this rectangle. The area is smaller still for normal winter bread wheat, $T$. vulgare ( $B h$ $B h)$, but as Hurd-Karrer has shown, short days and low temperatures will still give miracle heads. Presumably still shorter days with or without lower temperatures would give branched heads even in normal spring bread wheat.

There are limits outside which homozygous branched-headed $T$. turgidum itself will not produce miracle heads. With the late-spring sowing usually necessary for outdoor material in Leeds, in some years the pure lines show very little branching : one year, in fact, the only trace was the presence of occasional double spikelets at the base of the heads. Presumably this is due to the relatively early onset of long days in this latitude. With spring sowing, at any rate, it has never been possible to produce here the magnificent branched heads figured in the literature. The average reached is about that shown at $B$, although the parent head of this line (generously given by Mr. A. E. Watkins from his Cambridgegrown material) was considerably more branched.

It would seem that the branched-headed factor operates by altering the branched/normal-headed threshold and so can be made to behave as either a dominant or a recessive at will.

Botany Department,

University, Leeds 2.

'Percival, J., "The Wheat Plant" (London, 1921).

2 Hurd-Karrer, A. M., J. Agric. Res., 48, 867 (1933).

3 Arber, A., "The Gramineæ" (Cambridge, 1934).

\section{Simple Sensitive Flames}

IN his letter which appeared in NatuRE on March 25, Dr. Sutherland sets out to show, if I understand him aright, that a sensitive flame possesses certain very sharply defined frequencies of response, independent of the parameters of the jet, which is cer- tainly "surprising and dificult to explain", especially with this very heavily damped system. What exactly these frequencies are I am unable to decide from his diagram, since I note that two of the three sharply defined maxima of his lower diagram agree exactly with sharply defined minima in the upper diagram. Perhaps this is significant?

In the paper which he quotes ${ }^{1}$ I showed, working with a liquid-into-liquid jet, which is much better adapted for quantitative work than a flame, that these very sharp responses undoubtedly existed, but that many of the frequencies could be traced to resonances of the supporting structure, since they could be easily varied by loading it. I also brought forward evidence that the others were due to resonances of the room. Further, if the disturbance of the jet was produced by a small local vibrator, a centimetre or so from the orifice, which was too feeble to act appreciably on the framework or on the room, there was the same type of general response as was produced by the ordinary sound source but no selective response at all. This appeared to me conclusive.

If Dr. Sutherland should feel that the matter really needs "a critical comparative examination" of what he calls "the two claims" by an authority of weight, I venture to suggest that he start his investigation by repeating my experiment of vibrating in still air the orifice from which the flame issues. If he gets sharply defined response at the same frequencies as he now gets by using a heavy sound source in the room, which means vibrating the air past the orifice (and in my opinion, but not in his, also means producing resonant effects in room and structure), he will have gone some way to prove his point. If, however, he does not, he will be confronted with another conclusion, likewise surprising and difficult to explain, namely, that the motion of the orifice relative to the air produces a totally different effect from a like motion of the air relative to the orifice.

I failed to get any selective response at all when vibrating the orifice, either with a liquid jet or with a flame, although the general response was the same as with the normal procedure, but it would, needless to say, be a great satisfaction to me to have the result confirmed by Dr. Sutherland.

E. N. Da C. Andrade.

Royal Institution, Albemarle Street, London, W.1.

${ }^{1}$ Andrade, E. N. da C., Proc. Phys. Soc., 53, 329 (1941).

\section{The Sycamore Tree}

IN Mr. Alexander Howard's interesting article in NATURE of March 18 on the sycamore tree, he did not mention the very remarkable aeronautical properties of its seed. It is the outstanding example of Nature making use of the autogyro in flight, and with a single-winged rotor.

Attempts have been made to copy this extremely efficient method of parachuting, so to speak, but so far nothing comparable with the efficiency of the sycamore seed has been evolved.

It is also interesting as a demonstration of animate Nature using revolving mechanism, of which she is usually shy, but in this autogyro single-winged sycamore seed we have an example of a rotary movement combined with advanced aeronautics.

Brabazon of Tara.

70 Pall Mall, S.W.1. March 20. 